\title{
GAMMA RADIOGRAPHY IN INDUSTRY
}

\author{
BY \\ J. P. W. HUGHES and O. SHAW \\ From the North West, Merseyside, and North Wales Division of the Central Electricity Authority
}

(RECEIVED FOR PUBLICATION FEBRUARY 15, 1957)

The purpose of this paper is to describe the methods of using gamma radiography in testing boilers indestructively and the protection of persons exposed to radiation. Methods of detection and protection have been worked out in physics laboratories, at the atomic research establishments, and in hospitals, and no new principles are added. But a new problem of protection arises in industry where conditions are continually altering so that safe procedures are difficult to lay down in detail, and where the effects of overdosage are not immediately apparent, carelessness, foolhardiness, or common ignorance may cause disaster. Two examples of this will suffice.

One member of the team, despite being an excellent member of staff and a sensible and reliable man in every other way, was, for some inexplicable reason, continually over-irradiated and had to be removed from the team. The other was an epileptic who was employed for some time before this was discovered; considerable agility, skill, and speed are necessary in placing sources within boilers and fortunately this patient was discovered before he had endangered himself or others. Both men are working admirably and happily in other situations in the Division. No cases of illness due to exposure or serious overexposure occurred in the period under review.

The use of $x$ rays has been a familiar technique in the medical world for a long time and their application to metals and other structures in industry is also of fairly long standing. Radiography was, however, not widely practised in industry until artificial isotopes became commercially available soon after World War II. These isotopes are produced in atomic piles in various parts of the country, and those which are readily available and suitable for metal radiography are cobalt $^{60}$, iridium $^{192}$, and tantalum ${ }^{182}$.

One of the principal advantages offered by a source of one of these materials compared with an $x$-ray apparatus is its smallness. The large tubes, high tension leads, transformers, and other essential gear required for an $x$-ray apparatus are unnecessary and an artificial isotope can be conveniently used in small spaces. It has therefore become a practical proposition to anticipate metal failure in installed apparatus.

\section{Scope of the Tests}

The purpose of introducing radiography was to examine a large number of riveted drum boilers to detect any cracks which might be present between rivet holes. Experiments were carried out as early as $\mathbf{1 9 5 0}$ to determine whether the available sources, films, and ancillary apparatus, were suitable for this purpose. The North Western Division acquired their first source in January, 1951 (cobalt ${ }^{60}$ of $460 \mathrm{mC}$ strength), and so became a pioneer in this particular field of application. Later iridium ${ }^{192}$ was introduced because of its softer radiation.*

Defects in boilers may be caused by metal fatigue or by a combined chemical attack and mechanical stress producing a condition termed "caustic cracking ". It has been found that if the boiler water contains a certain proportion of caustic soda it will, at the temperature of operation of the plant, and with the mechanical and thermal stresses always present in boiler drum structures, produce very fine fissures along the grain boundaries of the metal; these may spread rapidly and increase in depth, chiefly along the planes of stress and may become serious enough to cause a boiler explosion.

Other uses we have made of gamma radiography are for examining castings for porosity, cracks, shrinkage, and inclusions, and increasingly for the purpose of testing welds in high pressure pipework for satisfactory workmanship.

Most boiler drums of the riveted type are made by bending a sheet of steel to the required shape and joining by means of "butt straps" along the

* The gamma energies given off by cobalt ${ }^{\circ 0}$ are $1 \cdot 17,1 \cdot 33 \mathrm{MeV}$. Those given off by iridium ${ }^{102}$ are $0.48,0.60,0.61 \mathrm{MeV}$, and others. Tantalum $^{102}$ gives off $1 \cdot 22,1 \cdot 13,0 \cdot 22,0 \cdot 15 \mathrm{MeV}$, and lower energies. 


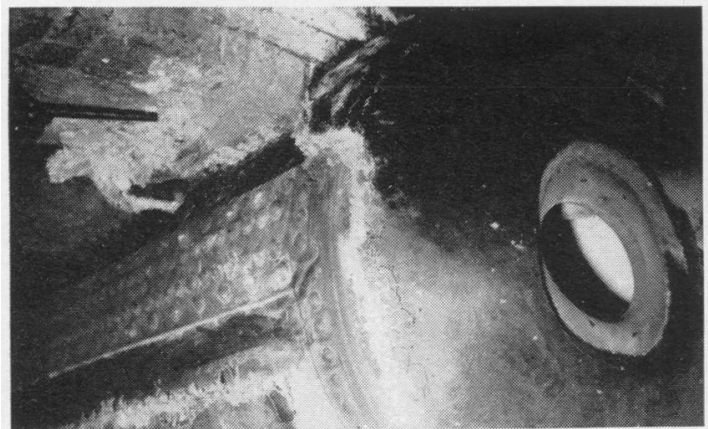

FIG. 1

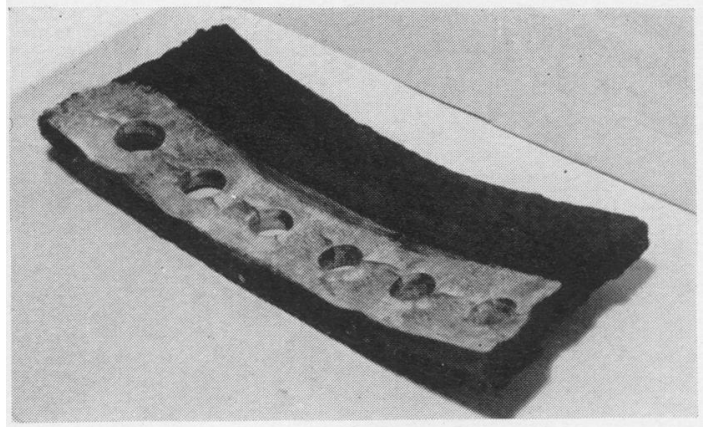

FIG. 2

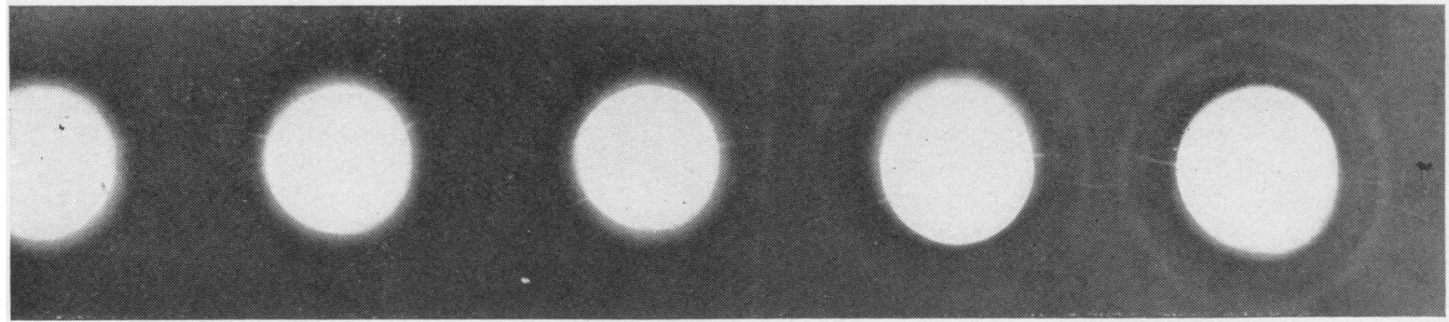

FIG. 3

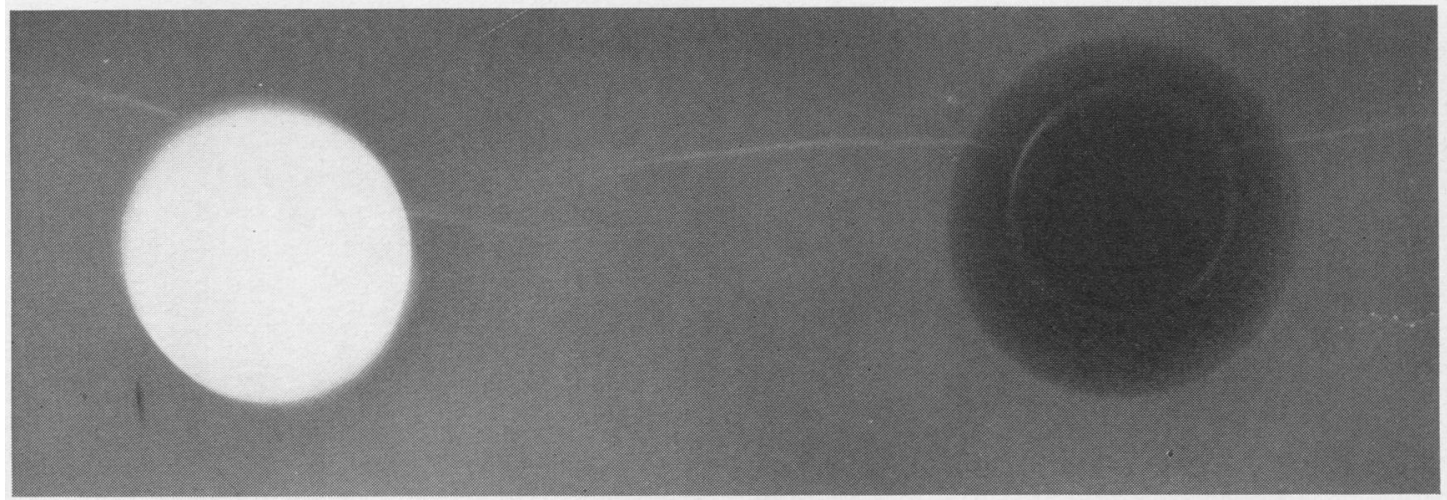

FIG. 4

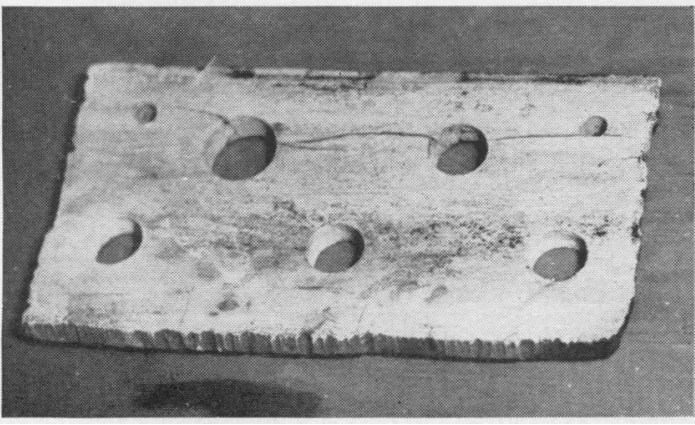

Fig. 5
Fig. 1.-Typical riveted drum showing the longitudinal "double butt strap" joint (only one strap on the outside) and the circumferential "lap" joint and access manhole.

FIG. 2.-Portion of a circumferential seam showing fatigue cracking.

Fig. 3.-Print from a radiograph of the portion illustrated in Fig. 2 (rivets removed).

FIG. 4.-Print from a radiograph of part of Fig. 5 (one rivet is in position). Note that definition of crack is less distinct under extra thickness of rivet head.

FIG. 5.-Extensive cracking in a butt strap (after dismantling). 


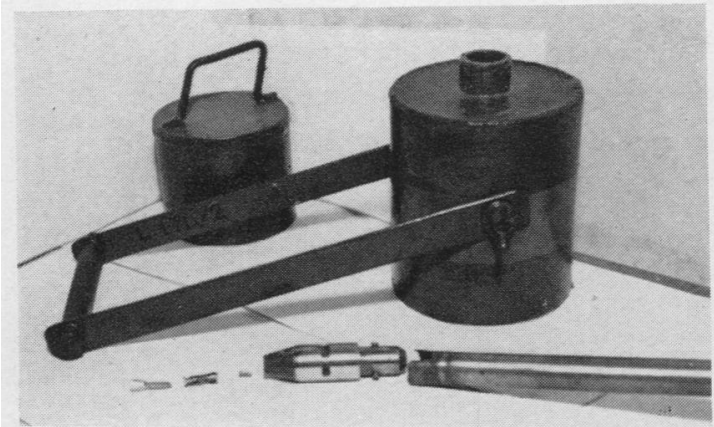

Fig. 6

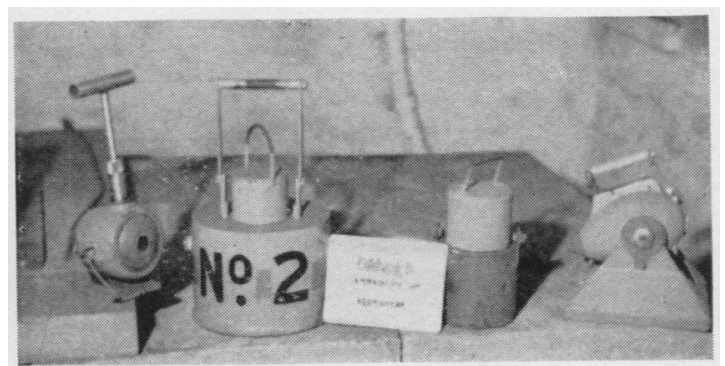

FIG. 8

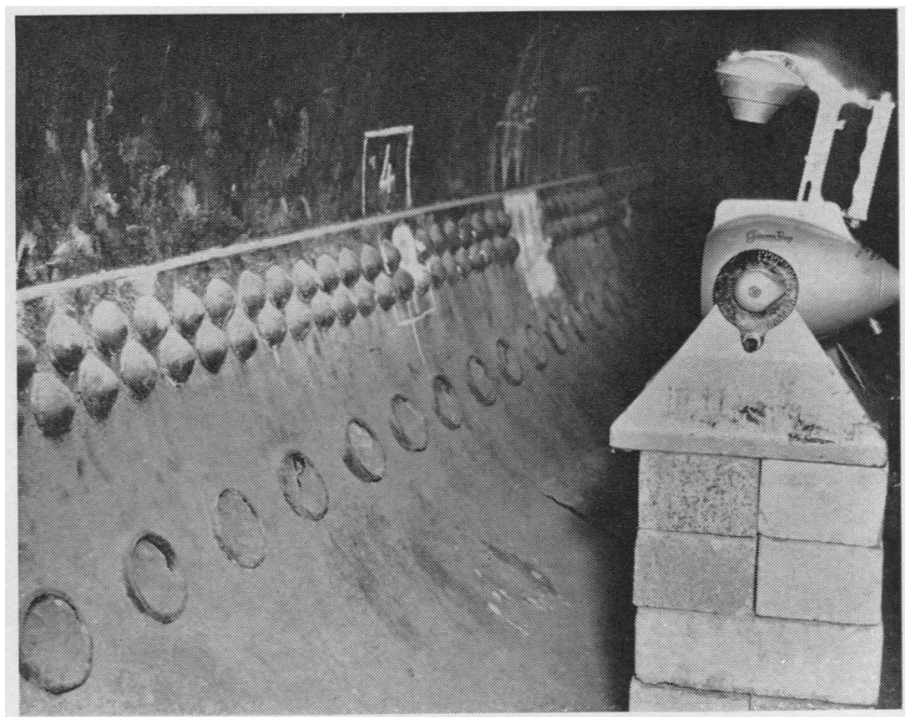

FIG. 7

Fig. 6. - The small items are, $L$ to $R: 6 \mathrm{~mm} . \times$ $6 \mathrm{~mm}$. capsule (to contain the "fill" of radioactive material), the capsule clip; clip screw; " bullet" or source holder; and part of $3 \mathrm{ft}$-long handling rod. Behind is one of the containers for a small source and its lid. Note the isotope serial number marked on the container handle.

Fig. 7.-Source container showing hinged nose open for taking one exposure on a longitudinal seam.

Fig. 8.-Various types of source containers. The one on the extreme right has a hinged lid on the nose.

FIG. 9.-Tripod shown in position for taking radiographs of a longitudinal seam (both sides simultaneously).

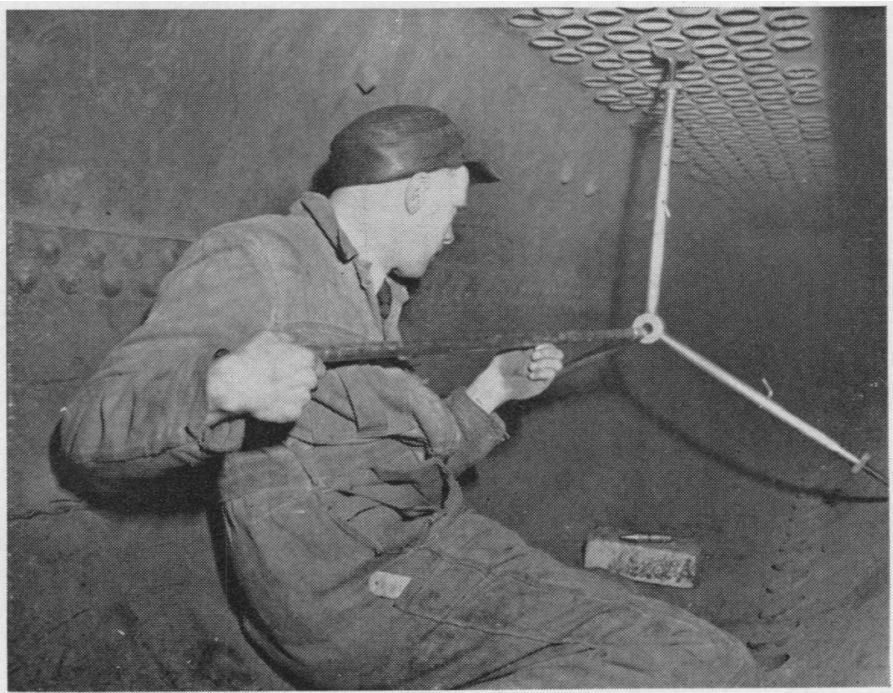

Fig. 9 
longitudinal joint, as shown in Fig. 1. The ends of the drum are covered with the end cap which is pierced by a manhole for access, and the cap is riveted to the shell, generally by a "lap joint".

Both these circumferential and longitudinal joints may be affected by cracking from one rivet hole to the next, as shown in Figs. 2 and 4 and in the gamma-ray plates 3 and 5 . This cracking invariably reaches danger point before it can be detected externally, and radiographs taken at suitable intervals therefore enable the defect to be detected before the danger level is exceeded.

\section{Apparatus Used}

Sources.-The activated isotope is contained in a capsule such as is shown in Fig. 6. There is a bayonet slot in the source holder for locking it in position in the container or the tripod boss. The capsule may be used in a variety of lead-lined containers, some of which can be used to emit a cone of radiation through a hinged window as shown in Fig. 7.

Containers. - Containers are calculated, measured, and certified fit to contain the radiation from a source of a certain strength, so that excessive radiation is not emitted from the outside surfaces. They are stored at a sufficient distance from personnel and films to avoid causing damage and they can be securely locked.

Containers are handled as remotely as possible. A trolley with a long handle or a long pole carried by two people can be used. If they are required above floor level, a simple pulley arrangement considerably reduces the radiation dosage received by the operators. The source is handled by means of a long pole of special design, by a Bowden cable extension, or by a long pair of tongs. The screening effect of brick, concrete, lead, and girders is exploited to reduce the radiation received by the men. When transported by car or van, a strong fixture is used to enable the container to be firmly anchored, and temporary lead slabs can be inserted between the source and the passengers as an additional safeguard. Various containers are illustrated in Fig. 8.

Films and Cassettes. - A range of types of films of proprietary make is available in various sizes, grades of speed, grain, and contrast. Generally, the lead screen technique is used. This uses the local scattering from the thickness of 0.01 in. to 0.015 in. lead foil placed in close contact with the film to intensify the image formed. Fine grain films are always preferable owing to the small size of defect to be detected, and these are used even at the expense of long exposure times. Cassettes may be metal or flexible plastic envelopes which can be press-studded together to form a band or chain round the circumferential seam or a portion of the longitudinal seam of the boiler drum.

Tripods.-Tripods are designed to hold a naked source in the centre of a boiler drum in order to take a panoramic radiograph of a circumferential seam using a band of up to 20 cassettes at one exposure. A tripod is shown in Fig. 9 and consists of three telescopic legs with screwed

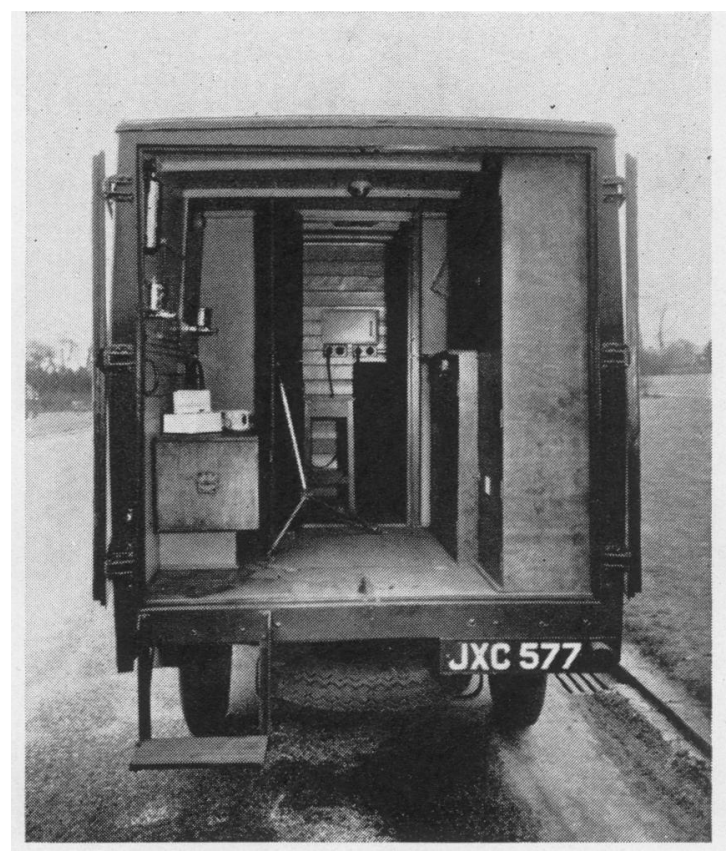

FIG. 10.-Van containing complete radiographic outfit for site investigations.

feet for fine adjustment and a central boss to hold the isotope.

After development of the film various types of illuminators have been used to enable a radiograph of any density to be satisfactorily scrutinized. Some radiographs are very dark and a viewing box of the type generally used in medical radiography is quite useless.

Mobile Unit.-All the apparatus can be carried in a standard 2-ton van modified for the purpose as illustrated in Fig. 10. The van has a lead-lined storage chamber for the isotopes and a dark room with a small developing unit and the tanks are fitted with water-tight lids. There is wiring for safelights, heaters, a drier, and an illuminator for viewing radiographs. This enables a complete examination and report to be made on the site in one visit.

\section{Method of Examination}

The source may be in its container using the hinged window (Fig. 7) or naked, for example, when a series of exposures is being made along a longitudinal seam (Fig. 9).

\section{Examples of Exposure Calculation}

The calculation of exposure time necessary is based on the following formula:-

Exposure time $\alpha \frac{\text { Drum thickness } \times(\text { drum radius) })^{2}}{\text { Source strength }}$

A suitable film to give a satisfactory radiograph, a source to suit the thickness of the metal involved, and a chart (Fig. 11) to calculate the exact exposure time are required. 


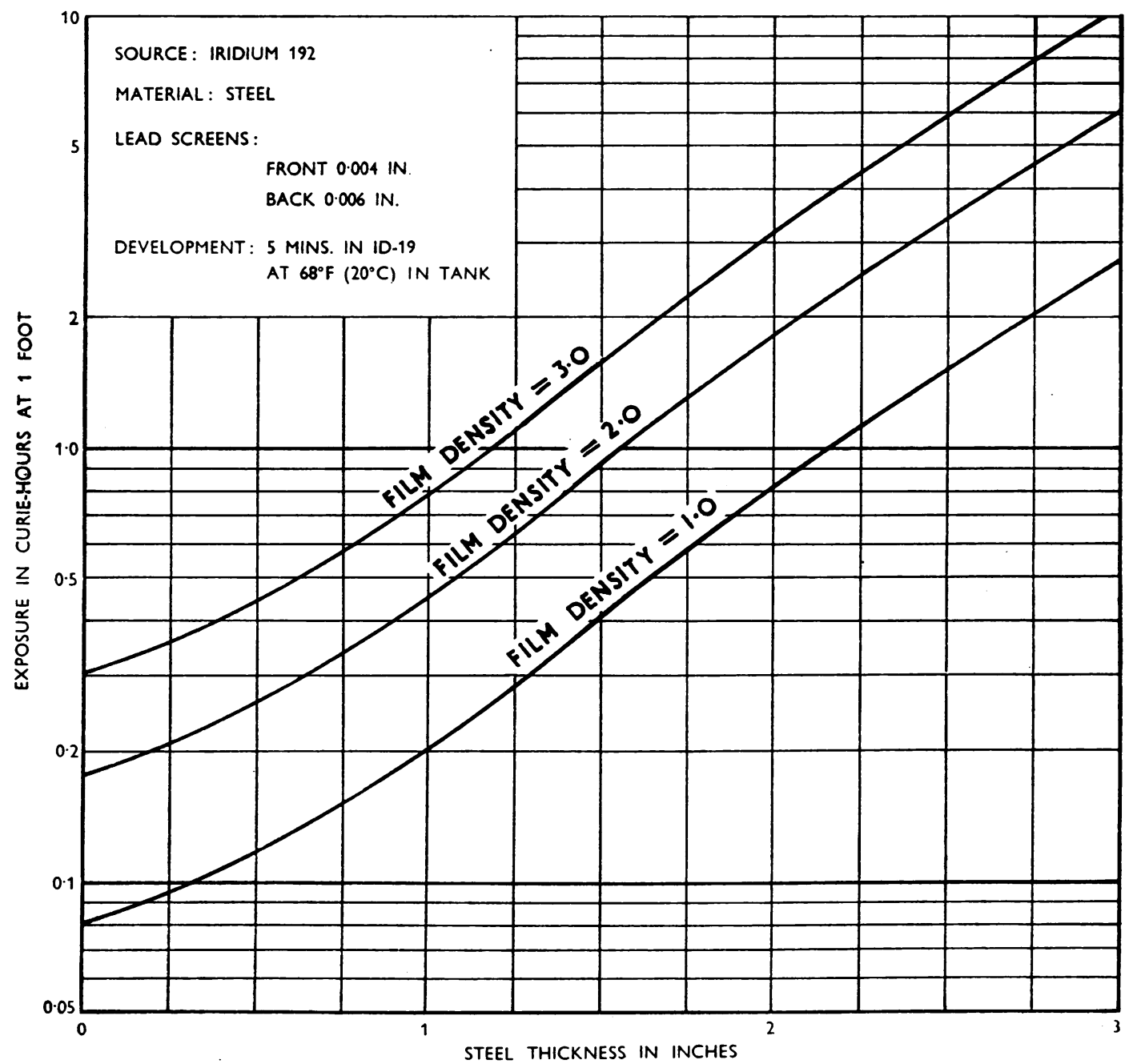

Fig. 11.-Typical exposure chart.

The calculations made for two boiler drums were as follows:-

\begin{tabular}{|c|c|c|}
\hline & Drum No. 1 & Drum No. 2 \\
\hline $\begin{array}{l}\text { Seam } \\
\text { Joint type } \\
\text { Plate thickness (in.) } \\
\text { Source film distance (in.) } \\
\text { Film type } \\
\text { Source } \\
\text { Strength (curies) } \\
\text { Exposure time (hours) }\end{array}$ & $\begin{array}{l}\text { Front circumferential } \\
\text { Lap } \\
2 \text { at } 8 \text { in. each } \\
19 \text { in. } \\
\text { Kodak Crystallex } \\
\text { Iridium }{ }^{192} \\
5.5 \\
1.75\end{array}$ & $\begin{array}{l}\text { Longitudinal } \\
\text { Double butt } \\
3 \text { at } 8 \text { in. each } \\
27 \text { in. } \\
\text { Kodak Crystallex } \\
\text { Cobalt } \\
1 \cdot 5 \\
3.375\end{array}$ \\
\hline
\end{tabular}

As the source decays in time the exact strength at the time of a particular exposure must be calculated and a chart has been constructed for this purpose. In the case of drum No. 1 above, the source was taken as at $5 \cdot 5$ curies and since the " half-life" of iridium is 70 days, then if a similar exposure were made 70 days later the source strength would be 2.75 curies and the exposure time 3.5 hours.

\section{Film Density}

This is a measure of the light transmitted through a particular film, and is expressed as the logarithmic ratio

of $\frac{\text { light incident }}{\text { light transmitted }}$. In general a film density of 1.7 to 2.0 is satisfactory, but it is common for radiographs of welds to be of a film density of over $2 \cdot 0$. To read these films a viewer with a 400 watt mercury vapour discharge lamp has been specially constructed.

Safety Aspects

Radiations from isotope sources are ionizing and this phenomenon offers a convenient method of measuring their intensity. The radiation monitor 
shown in Fig. 12 enables the " field strength" from an isotope to be measured in any location, and takes into account the effect of such natural shields as concrete, brickwork, and steelwork so that the limits of dangerous dosage may be defined and their boundaries marked out with tape and notices.

A divisional testing section consists of an engineer in charge, four staff engineers (or team leaders), and testing assistants. A team normally consists of one staff engineer and one or more testing assistants. Individuals are required to carry on their persons apparatus to estimate the dose received, particularly in the parts of the body likely to be most irradiated. It is often difficult to gain access to the flues, fire, and water spaces of a boiler to set up, operate, and dismantle radiographic apparatus so that it is rarely possible to make an accurate assessment of the dose likely to be received before any particular examination is completed. It has been firmly laid down that there are acceptable dosage levels per unit time and that these must on no account be exceeded. In order to avoid overdosage the fountain-pen type of dosimeter is used to give a continuous reading. This is a quartz fibre electroscope which is charged at regular intervals and discharged by the ionizing radiations from the source. It can be held up to the light and a direct reading taken at any time by the user to warn him whether he is approaching or has passed the level of safe dosage.

In the North Western Division the practice is to carry one of these dosimeters in the breast pocket and to supplement this with two standard film badges, one on the lapel and one on the wrist. In practice, it has been found that the lapel film badges compare closely with the readings obtained from the dosimeter, but that the wrist badges, being nearer the source, in most cases show a definitely higher reading. Both types of meter are considered desirable: the first for immediate checks at any time

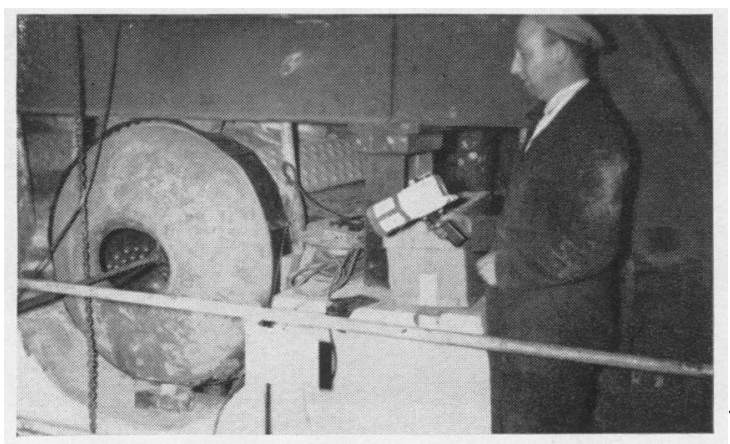

FIG. 12.-Radiation monitor being used to demarcate danger zone. Note the tripod just inside the manhole with source and handling rod in position; also the band of plastic cassettes linked together and covering this circumferential seam. and the $x$-ray badges because they are assessed by independent persons and form a permanent record of dosage; they do not need charging and are, if worn at all, foolproof.

In Government establishments at the time this work was undertaken, a reading of $0.5 \mathrm{r}$ a week on the film badge was considered to be equivalent to $0.3 \mathrm{r}$ body radiation and this was officially accepted as the maximum permissible weekly dose. In such establishments dosage can be rigorously controlled and the chance of an accidental sudden overdosage when a man has already received somewhere near the maximum permissible dose is unlikely. In the conditions described in this paper, however, a chance accidental overdose is by no means unlikely and it was decided to make a film badge reading of $0.3 \mathrm{r}$ the maximum permissible dose, and this figure is now accepted in Government establishments, not because the level has been lowered, but because the badge reading is now accepted as equivalent to the actual amount of radiation received; previously it was considered that back-scatter raised the reading artificially.

A weekly limit of $0.3 \mathrm{r}$ and a moving average of $0 \cdot 1 \mathrm{r}$ per week over 13 weeks were laid down as maximum permissible doses for this work. The difficulty with maximum permissible doses is that they are usually assumed to be tolerance doses. By using the dosimeters individuals can assess their dosage and if they have reached $0 \cdot 3 \mathrm{r}$ they are automatically suspended from further exposure. It was decided that " planned over-exposure" for certain categories of work should be agreed first by all concerned, including the medical department, but in practice it was found that over-exposures were unnecessary. The mounting evidence that when large exposures are made over a short period they cause greater body damage than when they are made over a longer period helped to curb enthusiasm for this type of project.

The 13-week moving average of $0 \cdot 1 \mathrm{r}$ per week was introduced in order to emphasize the difference between maximum permissible dosage and tolerance dose, only the latter being acceptable, and rest was enforced until the moving average was below this figure; fortunately there was adequate ancillary work for individuals without the necessity for them to be exposed to continuing radiation.

Medical opinion appears to be inclining more and more towards discarding routine blood counting but this is not yet fully understood by laymen. The first difficulty lies in the interpretation of individual counts since physiological variations and the results of minor infections produce such a broad band of "normal" that, unless a disaster occurred which would almost certainly be known, the count is useless 
for individual guidance. "Safe" dosages are those which do not produce physiological or pathological response and so such tests are pointless in those exposed to safe doses; where exposure has been excessive it can be checked by such means.

The blood count has three useful purposes: first, to ascertain any blood dyscrasia before exposure, that is, for the rejection of the unfit; secondly, to act as a base-line for an individual, because a fall from high to intermediate counts is of greater significance than persistently low counts, and progressive falls are more significant than isolated falls; and third, for assessment of damage after the agreed safe exposure has been exceeded, so that rest and blood transfusions may be ordered. On a group basis a fourth useful purpose may be mentioned, as counts classified as normal may show up group differences by a shift to higher or lower counts. The few men involved and variation in sources and exposure made it unrealistic to hope to gain any information by this means. The blood counts were, however, sent to the Christie Hospital, Manchester, for inclusion in their group readings. Since this hospital also undertook the interpretation of the film badges it was possible to relate dosage to the counts.

Three initial blood counts were taken before exposure, as there was nearly always a drop in the count from the first to the second specimen, due to excess circulating adrenalin from some degree of tension at the first examination. If the second and third showed disparity further counts were made. It was pointed out to the team individually that, together with the above arguments and the delay between exposure and blood changes, there was no place for blood counts in the control of exposure; their use was confined to ascertaining fitness in the first place and treatment in the event of accidents. Blood counts were not repeated unless the 13-week moving average exceeded $0.1 \mathrm{r}$ per week or the weekly exposure exceeded $0 \cdot 3 \mathrm{r}$ per week. No detailed information of the blood count was given to the individual.

It is arguable whether a court of law would consider that routine blood counts should be undertaken on all men however little they are exposed. Since idiopathic cases of leukaemia or other blood diseases may arise a haematological record is desirable but the chance of such a case in a group of this size after pre-employment normal counts is so slight as to be negligible. In large working groups the position is somewhat different. As the levels laid down for this work are considerably lower than the recommendations of the International Commission on Radiological Protection, it was considered that the employer's responsibility to his workers was fulfilled without subjecting them to routine blood counts which would be normal unless both the measurements of dosage employed failed or unless all $a$ priori reasoning on this question was at fault.

Apart from effects on the bone marrow the possibility of damage to gonads causing impaired fertility and to the lens of the eye causing cataract were considered. The lens is the most superficial organ (taken as $3 \mathrm{~mm}$. depth of tissue compared with bone marrow $5 \mathrm{~cm}$.) and the eyes must be directed at the source. In view of this and the inadequacy of any direct eye protection from lead glasses it was all the more important to insist on small exposure, and the avoidance of looking towards the source unnecessarily.

There are wide differences in workmen's attitudes to radioactivity. Some are alarmed that "a bomb" is in the work place at all, whereas others lack even elementary respect. Since only one of a row of boilers may have to be tested at any one time in this way, workmen occasionally needing to turn a valve of another boiler might have to enter the danger zone which had been monitored around the boiler being radiographed. In this event individuals were monitored in and out by members of the team in turn. This is safe practice but it raised some alarm in certain men who were concerned about the gonadal effect. There is some emotionally inspired muddled thinking on the difference between fertility and potency, and to combat this to some extent a record has been kept of the births of children to members of the team. No unusual findings were noted; three children have been born to members of the section in the last three years.

It has already been mentioned that the wrist film badge recorded higher exposure than the lapel badge. Initial effects of radiation were therefore more likely to occur on the master hand, and the hands of the team were examined for cracking or fissuring of the nails, erythema of the nail beds, and obliteration of the finger-prints. After some reassurance finger-printing was willingly accepted and the two hands could, in this way, be conveniently compared. A particular difficulty in diagnosis in these cases is that young engineers always appear to have motor-cycles which need constant mechanical attention with consequent trauma to the hands. With approved dosages, however, no differences have so far been detected between one hand and the other in members of the team.

\section{General Safety Measures}

It was agreed that men employed on the team should not be under 18 or over 45 years of age and that the numbers employed and the hours worked should ensure minimal exposure of any individual. 
Older men were excluded because they were not sufficiently agile and because they do not fit in very well socially in a young man's team which may be together for days on end. These safety standards were to be based on " maximum total man exposure" in the most difficult situations encountered in the field. For example, if experience showed that the complete examination of a certain piece of apparatus necessitated 1r of radiation in a week then 10 (or more) men should share the exposure.

Each individual was given a thorough general medical examination and any mental, emotional, or physical disability likely to cause over-exposure resulted in rejection as unfit for this work. The team's family doctors were informed that their patients were employed on this work and were kept informed of any over-exposures and abnormal medical findings. Four weeks' annual holiday, taken in one period, was recommended but rarely implemented.

A detailed record of sickness and accidents was kept to exclude the accident-prone individuals and to clarify doubtful sickness records. A chart of dosimeter and film badge readings for each individual was kept in the Medical Department and readings of both dosimeter and film badges were known to both engineers and the medical adviser. The team leader or his deputy, both authorized persons, were able to exclude men from radiation automatically without waiting for medical advice.

\section{Summary}

The methods of using gamma radiography in testing boilers indestructively in the North West Division of the Central Electricity Authority are described. An account is given of the protection of persons exposed to radiation. No cases of illness due to exposure or serious overexposure occurred in the period under review. The isotopes used were cobal $^{60}$ and iridium ${ }^{192}$, the latter being more satisfactory on account of its softer radiation. Gamma radiography enables metal failure to be anticipated in installed apparatus and thus reduces the danger of boiler explosions.

The methods of using the isotope sources within boiler drums are described and the principles of calculation of exposure times are given.

The protection of individuals is undertaken by two methods of monitoring: (a) the wearing of a "fountain-pen" type of dosimeter, and (b) the wearing of film badges on lapel and wrist. A weekly limit of $0.3 \mathrm{r}$ and a moving average of $0.1 \mathrm{r}$ per week over 13 weeks were laid down as maximum permissible doses for this work. The value of blood counts in assessing the exposure of individuals to radiation is discussed critically.

A chart of dosimeter and film badge readings is maintained for each individual member of the team engaged on work on radioactive isotopes; this chart gives weekly exposures and a 13-week moving average of exposures experienced.

Most of the medical detail was worked out in conjunction with Professor Lane and his staff in the Department of Occupational Health, Manchester University, and we also acknowledge with thanks help from many sources and in particular the constant help and advice of Mr. S. K. Stephenson, of the Christie Hospital and Holt Radium Institute, Manchester. We also wish to thank Mr. A. R. Cooper, Divisional Controller, and Mr. J. L. Ashworth, Chief Generation Engineer (Operation), of the Central Electricity Authority, North West, Merseyside and North Wales Division, for their permission to use the photographs and the information herein. 